\title{
Effect of training on muscle strength and motor function in the elderly
}

\author{
Rolf Frischknecht
}

Service de rhumatologie, Médecine physique et réhabilitation, Hôpital Nestlé, Centre hospitalier universitaire vaudois, 1011 Lausanne, Switzerland

(Received 12 February 1998; accepted 2 March 1998)

\begin{abstract}
Overall muscle strength and mass decline 30-50\% between the ages of 30 and 80 . The loss of muscle mass, the so called sarcopenia, accounts for most of the observed loss of strength. A reduced specific muscle force has also been observed but its contribution to the decrease in strength with age remains unclear. The loss of muscle tissue is due to a decrease in the number of muscle fibres and atrophy of the type II muscle fibres. The declining strength reduces the capacity to carry out basic activities of daily life and puts people at risk for falls and dependence. Resistive strength training greatly increases muscle strength even in very old people. It produces muscle fibre hypertrophy and improves neural factors involved in force production. The recovered strength in turn enhances the physical performance and allows a more active and independent life towards the end of the life span. (C) Inra/Elsevier, Paris
\end{abstract}

muscle strength / ageing / exercise

Résumé - Effet de l'entraînement sur la force musculaire et la performance fonctionnelle des personnes âgées. Force et masse musculaires diminuent de 30 à $50 \%$ entre l'âge de 30 ans et l'âge de 80 ans. La perte de masse musculaire explique presque entièrement la perte de force observée. Une diminution de la force spécifique a aussi été signalée, mais sa contribution à la diminution de la force musculaire avec l'âge reste controversée. La perte de tissus musculaires est due à la diminution du nombre total de fibres musculaires d'une part et à l'atrophie des fibres musculaires de type II d'autre part. La perte de fonction musculaire réduit la capacité d'effectuer les activités de base de la vie quotidienne et expose au risque de devenir dépendant d'autrui et de faire des chutes. Un entraînement de musculation dynamique avec machines ou haltères augmente grandement la force musculaire même chez des sujets d'âge très avancé. Ce type d'entrấnement $n$ 'améliore pas seulement des facteurs neuraux qui interviennent dans la génération de la force, mais induit aussi une hypertrophie musculaire. Le gain de force réalisé augmente à son tour les performances physiques du sujet âgé et lui permet de vivre une vie plus active et plus indépendante. (C) Inra/Elsevier, Paris

\section{force musculaire / vieillissement / entraînement}

* Correspondence and reprints

E-mail: Rolf.Frischknecht@ chuv.hospvd.ch 


\section{INTRODUCTION}

The proportion of elderly people is steadily increasing and this trend will continue well into the 21 st century. To enjoy independent living these people must retain as much as possible of their physical capacity to be able to perform common activities of daily living. Unfortunately muscle strength, one of the main determinants of function, decreases with age. This phenomenon has been referred to as sarcopenia and seems to be an inevitable accompaniment of ageing. It is important to understand the processes leading to this progressive loss of overall muscle force as it may help to develop strategies to limit the consequences of ageing on skeletal muscle.

\section{NATURAL EVOLUTION OF MUSCLE STRENGTH WITH AGE}

Overall muscle strength increases up to the age of 25 years. Peak strength in young women is about $66 \%$ of that of young men. From the age of 30 years onward, muscle strength declines progressively $[4,8,24,27]$. The loss of force is moderate up to the age of 50 years but increases to about $15 \%$ per decade between 50 and 70 years of age [27]. After the age of 70 years there is a further acceleration of the decline and as much as $30 \%$ of muscle strength may be lost between 70 and 80 years $[2,14]$. The overall loss of force between 30 and 80 years of age is $40-50 \%$ in leg and back muscles and $30-40 \%$ in arm muscles [3, 22, 25, 37]. The loss of strength has been found to be similar in men and women $[27,41]$. Women have a peak of muscle strength which is substantially lower and occurs earlier in life compared to men. Therefore they are more likely to see their muscle force drop below the critical level where common activities of daily living can no longer be performed independently.

The decrease in muscle force observed with age is not uniform in all muscle groups and substantial variation can be observed. Leg force decreases much quicker than arm force, whereas trunk muscles show an intermediate pattern [3]. It is important to take this into account if functional consequences of sarcopenia are discussed.

Cross-sectional studies tend to underestimate the loss of strength with age as very frail subjects may not been included into such studies. It might be correct to study only subjects in good health to describe the natural decline of muscle function in order to isolate the effect of ageing from diseases which might affect muscle function as well. However, the difference between frailty due to normal ageing and pathological frailty is not clear cut. Longitudinal studies give us a much better idea about the number of elderly people with functional difficulties because of loss of muscle force. However, they are difficult to carry out over long periods of time due to drop outs. It is also difficult to include invasive procedures into such studies for obvious reasons. Only few longitudinal studies are available. Bassey and Harries [5] demonstrated clearly how cross-sectional studies can underestimate the loss of strength with age. They also show that nonagenarians, especially women, can reach levels of strength which are so low that their functional capacity must be severely impaired.

\section{MECHANISMS OF THE LOSS OF MUSCLE STRENGTH}

As muscle strength declines with age so does muscle size [38]. The decrease in muscle mass seems to account for most of the loss of strength reported as both 
decrease to a similar extent $[19,29,33$, $41,42]$.

The cross-sectional area of skeletal muscles decreases more than the crosssectional area of individual muscle fibres in biopsy samples. Grimby and Saltin [22] concluded that muscle fibre atrophy cannot be the only reason for the loss of muscle size in the elderly, but that a loss of muscle fibres must take place. Lexell et al. [29] were able to show a progressive reduction with age of the total number of muscle fibres in the vastus lateralis muscles of accidentally deceased people. In their study the loss of muscle cross-sectional area started even before the age of 30 , reached $10 \%$ at the age of 50 , then accelerated to reach a total of $40 \%$ at the age of 80 . The loss of muscle fibres seems to touch evenly the different muscle fibre types as no change in muscle fibre composition takes place in the ageing muscles $[1,2,29]$. The age-related loss of muscle fibres may be related either to a loss of motor units or to a decrease in the size of the motor unit territories. EMG studies suggest a decrease in the total number of motor units per muscle and an increase in the motor unit territories $[9,12,20,34]$. These findings and the observation of fibre-type grouping [28] suggest that part of the muscle fibres which lose their innervation due to a decrease in the number of motor units is taken over by axonal sprouting by neighbouring motor units. The loss of motor units might be the result of a loss of motoneurons due to the ageing process. Tomlinson and Irving [36] reported a progressive loss of ventral horn cell bodies in the human lumbosacral cord. This process started at the age of 60 and by the age of 95 one third of the cell bodies were lost. Furthermore a reduction of large myelinated nerve fibres in human thoracic ventral roots with age has been reported by Corbin and Gardiner [13]. The loss started around the age of 30 and by the age of 90 years $40 \%$ of the myelinated axons had disappeared. The loss of muscle fibres seems not to be related to decreased activity with age. The average speed of the men's $200 \mathrm{~m}$ sprint world record declines with age in line with the decrease in leg muscle strength, which means that even highly active subjects lose muscle mass and strength with age.

Muscle fibre atrophy also takes place in the ageing muscle but its contribution to the decrease in strength is less than the loss of muscle fibres [21, 22]. Individual type I muscle fibres seem to keep their cross-sectional area unchanged up to the age of $80[1,29]$. In the quadriceps femoris type IIA and IIB fibres undergo a significant atrophy of around $26 \%$ between 20 and 80 years of age [29]. Type IIB fibres seem to be more affected than IIA fibres [1]. In the biceps brachii muscle the situation is quite different. There seems to be very little or no atrophy of type II muscle fibres $[1,23]$.

A reduction in specific force (force per unit of cross-sectional area) with age has been reported in the quadriceps femoris of men [25, 42], biceps brachii/brachialis in men [25] and adductor pollicis [10]. However, Young et al. [41] did not find a similar decrease in specific force in the quadriceps femoris in women. The factors contributing to the loss of specific force are not well established. Lexell et al. [29] found an increase in connective tissue with age in the human vastus lateralis. The relative decrease in the total cross-sectional area of the fast type II fibres due to the selective atrophy of these fibres may also reduce the specific force as slow muscle fibres have a slightly lower normalized force than fast ones [10]. The increase of slow type myosins and the decrease of fast type myosin isoformes [25] without any change in muscle fibre distribution suggest a change in contractile properties of the ageing muscle. However, the changes in myosin heavy chain composition seem to reflect changes in rela- 
tive fibre type areas of type I, IIA and IIB fibres with age [25]. Recently Delbono et al. [15] reported a decreased voltage and calcium-dependant calcium release in fast single fibres from aged human skeletal muscle. The amount of calcium available to trigger the contractile response in these muscle fibres seems to be reduced.

\section{FUNCTIONAL CONSEQUENCES OF THE LOSS OF STRENGTH WITH AGE}

It is now well established that the declining strength with age reduces the physical performance capacity of the elderly. Bassey et al. [6] found walking speed to be related to calf strength in men as well as in women. In men the weekly amount of walking was also dependent on leg muscle strength [6]. In addition, leg extensor power correlates with the speed of chair raising, stair climbing and walking [7].

Isokinetic peak torque and power of knee flexors and extensors as well as ankle flexors and extensors were found to be much lower in subjects with a history of one or more unexplained fall the year preceding the force assessment [39]. Wolfson et al. [40] also report a strong relationship of balance to strength and walking speed. Impaired chair raising capacity and poor arm force have also been reported as risk factors for falls [35]. It appears that the agerelated loss of muscle mass and strength might be a critical determinant of functional loss, dependence and disability [11].

\section{CAN LOSS OF MUSCLE DUE TO AGE BE PREVENTED?}

The decline of maximal voluntary strength and muscle mass with age raises the question of how these changes can be counteracted or prevented. The decrease in the $200 \mathrm{~m}$ sprint world record with increasing age suggests that the changes due to age are not entirely preventable even in highly active subjects [31]. However, activity may have a beneficial influence on the atrophy component of the loss of muscle mass.

Klitgaard et al. [25] compared young men in their late 20 s with elderly active or sedentary men approaching 70 years of age. The active men were practising their favourite sport (swimming, running or resistive strength training) at least three times a week over the 12-17 years preceding the study. Maximal isometric knee extensor torque, cross-sectional quadriceps area, mean quadriceps muscle fibre area and specific quadriceps force were found to be lower in the elderly sedentary men compared to the group of young men (decrease of 44, 24, 24 and $20 \%$, respectively). Slightly better values were found in the elbow flexors.

In the elderly men practising a regular strength training maximal isometric torque, cross-sectional muscle area, mean fibre cross-sectional area and myosin isoform distribution of the knee extensor and the elbow flexor were similar to that seen in young sedentary adults. Elderly swimmers and runners did not differ from the sedentary group except runners who showed a tendency for higher knee extension torque. Running, swimming and strength training were able to restore the decreased specific force seen in sedentary elderly men. These findings suggest that regular strength training allows to limit, the age-induced loss of muscle mass and strength, whereas this is not the case for running and swimming.

\section{STRENGTH TRAINING IN THE ELDERLY}

In young individuals a resistive strength training induces a substantial increase in 
muscle mass and force (see [26] for a review). It induces an increase in the mean cross-sectional area of both type I and type II muscle fibres although the hypertrophy seems to be greater in type II fibres compared to type I fibres. The contribution of muscle fibre hyperplasia to the increase in muscle mass remains controversial. Muscle force generation depends also on neural factors such as the extent of recruitment of motor units, the intensity of the drive of the recruited units and the intramuscular co-ordination. Furthermore the overall strength of a muscle group is determined by the intermuscular co-ordination, the agonist-antagonist interplay and the quality of the motor programmes. The improvement of neural factors leads to a rapid initial increase of force production at the beginning of a strength training, whereas hypertrophy takes more time to develop [32].

There is now plenty of evidence that elderly people practising an appropriate resistive strength training can achieve results that are similar to those seen in the young [33].

Moritani and de Vries [32] trained the elbow flexors of a group of young male subjects (18-26 years old) and a group of aged males (67-72 years old) using isotonic progressive dumbbell exercises. The training regimen was ten repetitions twice a day, three times a week for 8 weeks. The load was adjusted every 2 weeks to $66 \%$ of the one repetition maximum. The one repetition maximum is the load which allows completion of just one entire movement and is often abbreviated $1 \mathrm{RM}$. The muscle strength increased by $28 \%$ in the young and by $23 \%$ in the aged. Although the increase in muscle strength was very similar in both groups, the young developed a much greater muscle hypertrophy than the aged ( 9 versus $3 \%$ ). On the other hand, the aged improved their ability to activate their muscles electrically much more than the young, allowing them to compensate for the poorer muscle hypertrophy.

Frontera et al. [18] trained the knee flexors and extensors of healthy male volunteers aged 60 to 72 . The training regimen was three sets of eight repetitions, three times a week for 12 weeks. The training load was kept at $80 \%$ of the one repetition maximum ( $1 \mathrm{RM}$ ) through weekly strength assessments. The one repetition maximum for knee extensors and flexors increased by 112 and $227 \%$, respectively. Isokinetic concentric extensor and flexor force increased by 9 and $17 \%$, respectively, at $60 \%$ and $16 \%$ at $240 \%$. Total cross-sectional area of all thigh muscles or quadriceps taken individually was found to be up $11 \%$. The mean cross-sectional area of vastus medialis type I and type II muscle fibres increased by 33 and $28 \%$. No change in the muscle fibre distribution was observed.

Meredith et al. [30] studied the combined effect of strength training and nutritional supplementation in a group of sedentary men aged 61-72. Muscle crosssectional area and 24-h creatinine excretion increased significantly more in subjects receiving a nutritional supplement, whereas muscle strength augmented similarly in both groups.

\section{STRENGTH TRAINING IN VERY OLD ADULTS}

The dramatic improvement of muscle function by a resistive strength training in people in their 70 s raises the question as to whether similar results could be achieved in people over 80 or 90 years of age.

Fiatarone et al. [16] trained frail male and female nursing home residents aged 86-96. To strengthen their quadriceps the subjects practised three sets of eight concentric and eccentric repetitions three times a week for 8 weeks. The training load was set at $80 \%$ of the one repetition 
maximum (1 RM) and adjusted every 2 weeks. The training regimen was well tolerated. Only one man was asked to stop the work outs because of a straining sensation in the groin located at a previously operated inguinal hernia. Quadriceps muscle strength increased by $174 \%$ and quadriceps cross-sectional area by $11 \%$. Tandem gait speed was found to be related to quadriceps strength and improved by $48 \%$ during the 8-week training period. Unfortunately the increase in strength was lost again 4 weeks after the subjects resumed normal life.

In a more complete study Fiatarone et al. [17] enrolled men and women aged 72-98 living in a long-term care facility. In the training group the subjects exercised their knee and hip extensors three times a week for 10 weeks. A training session included three sets of eight repetitions for each muscle group. The load, $80 \%$ of the one repetition maximum ( $1 \mathrm{RM})$, was adjusted at each training session. Training increased muscle strength and crosssectional area of the thigh muscles by $113 \%$ and about $3 \%$, respectively. In the control group muscle cross-sectional area decreased by $2 \%$. The training also increased gait velocity by $12 \%$ and stair climbing power by $28 \%$. Strength gain tended to be higher in subjects given a nutritional supplement (137 versus $88 \%$ ). Interestingly the strength training also increased the level of spontaneous activity by $34 \%$, whereas control subjects became $5 \%$ less active. This observation means that the trained subjects used their newly acquired force to increase their daily activity.

These studies show that a resistive strength training is effective over the whole life span of adult life. The strength gained seems to be used spontaneously in every day life which again suggests that the loss of strength is an essential factor for the decrease in activity seen in the elderly. Strength training may disrupt a vicious circle wherein decreased strength generates sedentarity which in turn leads to further atrophy.

\section{CONCLUSION}

There is evidence for a loss of overall muscle strength with age. This process accelerates progressively towards the end of human life span and is mainly due to a decrease in the total number of muscle fibres and an atrophy of the remaining muscle fibres. The atrophy is much more pronounced in type II fibres. The decrease in muscle strength leads to incapacity in elderly people. A resistive muscle training greatly increases muscle strength even in the very old by improving neural factors and inducing muscle hypertrophy. The increased strength in turn allows improvement of functional activities of daily living such as walking, raising from a chair and climbing stairs. At the present state of knowledge sarcopenia is an inevitable process related to ageing. However, the loss of muscle tissue can be attenuated by an appropriate strength training which should begin no later than the age of 50 when skeletal muscle loss starts to accelerate [37]. Nutritional aspects must be considered when a strength training is initiated. Insufficient protein and calorie intake should be corrected to obtain maximal results.

\section{REFERENCES}

[1] Aniansson A., Hedberg M., Henning G.B., Grimby G., Muscle morphology, enzymatic activity and muscle strength in elderly men: a follow up study, Muscle Nerve 9 (1986) 585-591.

[2] Aniansson A., Grimby G., Hedberg M., Compensatory muscle fibre hypertrophy in elderly men, J. Appl. Physiol. 73 (1992) 812-816.

[3] Asmussen E., Aging and exercise, in: Horvath S.M., Yousef M.K. (Eds.), Environmental Physiology: Aging, Heat and Altitude, Elsevier, New York, 1980, pp. 419-428. 
[4] Bassey E.J., Old age, less strength, The Physiological Society Magazine No. 11, 1994, p. 16.

[5] Bassey E.J., Harries U.J., Normal values for handgrip strength in 920 men and women over 65 years, and longitudinal changes over 4 years in 620 survivors, Clin. Sci. 84 (1993) 331-337.

[6] Bassey E.J., Bendall M.J., Pearson M., Muscle strength in the triceps surae and objectively measured customary walking activity in men and women over 65 years of age, Clin. Sci. 74 (1988) 85-89.

[7] Bassey E.J., Fiatarone M.A., O'Neill E.F., Kelly M., Evans W.J., Lipsitz L.A., Leg extensor power and functional performance in very old men and women, Clin. Sci. 82 (1992) 321-327.

[8] Borges O., Isometric and isokinetic knee extension and flexion torque in men and women aged $20-70$, Scand. J. Rehabil. Med. 21 (1989) 45-53.

[9] Brown W.F., A method for estimating the number of motor units in thenar muscles and the changes in motor unit content with aging, J. Neurol. Neurosurg. Psych. 35 (1972) 845-852.

[10] Bruce S.A., Newton D., Woledge R.C., Effect of age on voluntary force and cross-sectional area of human adductor pollicis muscle, Q. J. Exp. Physiol. 74 (1989) 359-362.

[11] Buchner D.M., Beresford S.A., Larson E.B., La Croix A.Z., Wagner E.H., Effects of physical activity on health status in older adults. II. Intervention studies, Annu. Rev. Public Health 13 (1992) 469-488.

[12] Campbell M.J., McComas A.J., Petito F., Physiological changes in ageing muscles, J. Neurol. Neurosurg. Psych. 36 (1973) 74-82.

[13] Corbin K.B., Gardiner E.D., Decrease in number of myelinated fibres in human spinal roots with age, Anat. Rec. 68 (1937) 63-74.

[14] Danneskiold-Samsoe B., Kofold V., Munter J., Grimby G., Schnohr P., Jensen G., Muscle strength and functional capacity in 78-81 year old men and women, Eur. J. Appl. Physiol. 52 (1984) 310-314.

[15] Delbono O., O'Rourke K.S., Ettinger W.H., Excitation-calcium release uncoupling in aged single human skeletal muscle fibers, J. Membrane Biol. 148 (1995) 211-222.

[16] Fiatarone M.A., Marks E.C., Ryan N.D., Meredith C.N., Lipsitz L.A., Evans W.J., High-intensity strength training in nonagenarians - effects on skeletal muscle, JAMA 263 (1990) 3029-3034.

[17] Fiatarone M.A., O'Neill E.F., Ryan N.D., Clements K.M., Solares G.R., Nelson M.E., Roberts S.B., Kehaylas J.J., Lipsitz L.A., Evans W.J., Exercise training and nutritional supplementation for physical frailty in very elderly people, N. Engl. J. Med. 330 (1994) 1769-1775.

[18] Frontera W.R., Meredith C.N., O'Reilly K.P., Knuttgen H.G., Evans W.J., Strength conditioning in older men: skeletal muscle hypertrophy and improved function, J. Appl. Physiol. 64 (1988) 1038-1044.

[19] Frontera W.R., Hughes V.A., Lutz K.J., Evans W.J., A cross-sectional study of muscle strength and mass in 45- to 78-year-old men and women, J. Appl. Physiol. 71 (1991) 644-650.

[20] Galea V., Changes in motor unit estimates with aging, J. Clin. Neurophysiol. 13 (1996) 253-260.

[21] Grimby G., Muscle performance and structure in the elderly as studied cross-sectionally and longitudinally, J. Gerontol. 50A (1995) 17-22.

[22] Grimby G., Saltin B., Mini-review The ageing muscle, Clin. Physiol. 3 (1983) 209-218.

[23] Grimby G., Danneskiold-Samsoe B., Hvid K., Saltin B., Morphology and enzymatic capacity in arm and leg muscles in 78-81 year old men and women, Acta Physiol. Scand. 115 (1982) 125-134.

[24] Hollmann W., Hettinger Th., Sportmedizin - Arbeits - und Trainingsgrundlagen, Schattauer, Stuttgart, 1980, pp. 202-205.

[25] Klitgaard H., Mantoni M., Schiaffino S., Ausoni S., Gorza L., Laurent-Winter C., Schnohr P., Saltin B., Function, morphology and protein expression of ageing skeletal muscle: a cross-sectional study of elderly men with different training backgrounds, Acta Physiol. Scand. 140 (1990) 41-54.

[26] Kraemer W.J., Deschenes M.R., Fleck S.J., Physiological adaptations to resistance exercise, Sports Med. 6 (1988) 246-256.

[27] Larsson L., Grimby G., Karlsson J., Muscle strength and speed of movement in relation to age and muscle morphology, J. Appl. Physiol.: Resp. Environ. Exercise Physiol. 46 (1979) 451-456.

[28] Lexell J., Downham D., Sjöström M., Distribution of different fibre types in human skeletal muscle: fibre type arrangement in $\mathrm{m}$. vastus lateralis from three groups of healthy men between 15 and 83 years, J. Neurol. Sci. 72 (1986) 211-222.

[29] Lexell J., Taylor C.C., Sjöström M., What is the cause of the ageing atrophy? Total number, size and proportion of different fiber types studied in whole vastus lateralis muscle from 15- to 83-year-old men, J. Neurol. Sci. 84 (1988) 275-294.

[30] Meredith C.N., Frontera W.R., O'Reilly K.P., Evans W.J., Body composition in elderly men: effect of dietary modification during 
strength training, J. Am. Geriart. Soc. 40 (1992) 155-162.

[31] Moore II D.H., A study of age group track field records to relate age and running speed, Nature 253 (1975) 264-265.

[32] Moritani T., de Vries H.A., Potential for gross muscle hypertrophy in older men, J. Gerontol. 35 (1980) 672-682.

[33] Rogers M.A., Evans W.J., Changes in skeletal muscle with aging: Effects of exercise training, Exercise Sport Sci. Rev. 21 (1993) $65-102$.

[34] Stalberg R., Fawcett P.R.W., Macro EMG in healthy subjects of different ages, J. Neurol. Neurosurg. Psych, 45 (1982) 870-878.

[35] Tinetti M.E., Inouye S.K., Gill T.M., Doucette J.T., Shared risk factors for falls, incontinence and functional dependence, JAMA 273 (1995) 1348-1353.

[36] Tomlinson B.E., Irving D., The numbers of limb motor neurones in the human lumbosacral cord throughout life, J. Neurol. Sci. 34 (1977) 213-219.
[37] Tseng B.S., Marsh D.R., Hamilton M.T., Booth F.W., Strength and aerobic training attenuate muscle wasting and improve resistance to the development of disability with aging, J. Gerontol. 50A (1995) 113-119.

[38] Tzankoff S.P., Norris A.H., Effect of muscle mass decrease on age related BMR changes, J. Appl. Physiol. 43 (1977) 1001-1006.

[39] Whipple R.H., Wolfson L.I., Amerman P.M., The relationship of knee and ankle weakness to falls in nursing home residents: an isokinetic study, J. Am. Geriatr. Soc. 35 (1987) 13-20.

[40] Wolfson L., Judge J., Whipple R., King M., Strength is a major factor in balance, gait and the occurrence of falls, J. Gerontol. 50A (1995) 64-67.

[41] Young A., Stokes M., Crowe M., Size and strength of quadriceps muscles of old and young women, Eur. J. Clin. Invest. 14 (1984) 282-287.

[42] Young A., Stokes M., Crowe M., The size and strength of the quadriceps muscles of old and young men, Clin. Physiol. 5 (1985) $145-154$. 